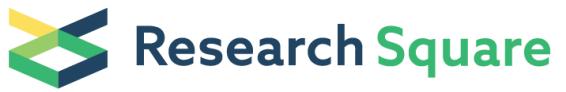

Preprints are preliminary reports that have not undergone peer review.

They should not be considered conclusive, used to inform clinical practice,

or referenced by the media as validated information.

\section{Effect of Meloxicam on Behavior, Physiology and Pain Sensitivity in Holstein Calves Following Dehorning}

\section{Zhiqiang Li}

Key Laboratory of Animal Disease and Human Health of Sichuan Province, College of Veterinary Medicine, Sichuan Agricultural University

\section{Yulong Zhang}

Key Laboratory of Animal Disease and Human Health of Sichuan Province, College of Veterinary Medicine, Sichuan Agricultural University

Yaocheng Cui

Key Laboratory of Animal Disease and Human Health of Sichuan Province, College of Veterinary Medicine, Sichuan Agricultural University Jianchen Qi

Key Laboratory of Animal Disease and Human Health of Sichuan Province, College of Veterinary Medicine, Sichuan Agricultural University

\section{Dongjie Cai}

Key Laboratory of Animal Disease and Human Health of Sichuan Province, College of Veterinary Medicine, Sichuan Agricultural University

Jing Fang

Key Laboratory of Animal Disease and Human Health of Sichuan Province, College of Veterinary Medicine, Sichuan Agricultural University

Tianyu Tan

Key Laboratory of Animal Disease and Human Health of Sichuan Province, College of Veterinary Medicine, Sichuan Agricultural University

Huawei Zou

Animal Nutrition Institute, Sichuan Agricultural University

Yue Xie

Key Laboratory of Animal Disease and Human Health of Sichuan Province, College of Veterinary Medicine, Sichuan Agricultural University Hongrui Guo

Key Laboratory of Animal Disease and Human Health of Sichuan Province, College of Veterinary Medicine, Sichuan Agricultural University

\section{Shiyi Chen}

College of animal Science and Technology, Sichuan Agricultural University

Jun Yi

Sichuan Academy of Agricultural Sciences

Wei Wang

Sichuan Academy of Agricultural Sciences

\section{Xiaoping Ma}

Key Laboratory of Animal Disease and Human Health of Sichuan Province, College of Veterinary Medicine, Sichuan Agricultural University

\section{Liping Gou}

Key Laboratory of Animal Disease and Human Health of Sichuan Province, College of Veterinary Medicine, Sichuan Agricultural University Hengmin Cui

Key Laboratory of Animal Disease and Human Health of Sichuan Province, College of Veterinary Medicine, Sichuan Agricultural University

Yi Geng

Key Laboratory of Animal Disease and Human Health of Sichuan Province, College of Veterinary Medicine, Sichuan Agricultural University

Ming Zhang

College of animal Science and Technology, Sichuan Agricultural University

\section{Gang Ye}

Key Laboratory of Animal Disease and Human Health of Sichuan Province, College of Veterinary Medicine, Sichuan Agricultural University

\section{Zhijun Zhong}

Key Laboratory of Animal Disease and Human Health of Sichuan Province, College of Veterinary Medicine, Sichuan Agricultural University

\section{Zhihua Ren}

Key Laboratory of Animal Disease and Human Health of Sichuan Province, College of Veterinary Medicine, Sichuan Agricultural University Yanchun Hu

Key Laboratory of Animal Disease and Human Health of Sichuan Province, College of Veterinary Medicine, Sichuan Agricultural University Ya Wang 
Key Laboratory of Animal Disease and Human Health of Sichuan Province, College of Veterinary Medicine, Sichuan Agricultural University Junliang Deng

Key Laboratory of Animal Disease and Human Health of Sichuan Province, College of Veterinary Medicine, Sichuan Agricultural University

\section{Shuming Yu}

Key Laboratory of Animal Disease and Human Health of Sichuan Province, College of Veterinary Medicine, Sichuan Agricultural University

Suizhong Cao

Key Laboratory of Animal Disease and Human Health of Sichuan Province, College of Veterinary Medicine, Sichuan Agricultural University

Zhicai Zuo ( ZZCJL@126.COM)

Key Laboratory of Animal Disease and Human Health of Sichuan Province, College of Veterinary Medicine, Sichuan Agricultural University

Zhisheng Wang

Animal Nutrition Institute, Sichuan Agricultural University

\section{Research Article}

Keywords: meloxicam , feed intake, physiology , pain sensitivity, calves

Posted Date: December 9th, 2020

DOI: https://doi.org/10.21203/rs.3.rs-116984/v1

License: @ (i) This work is licensed under a Creative Commons Attribution 4.0 International License. Read Full License 


\section{Abstract}

The present work aimed to assess the effects of meloxicam on the behavior, feed intake, physiology and pain sensitivity in calves following dehorning. Calves were randomly allocated to four groups: dehorning by amputation with saline (ADNM) or meloxicam (ADM) and chemical disbudding with saline (CDNM) or meloxicam (CDM). Significant differences in the frequencies of all behaviors and activity levels were not observed for the treatment*time interaction $(p \geq 0.05)$ but were observed for time points $(p<0.05)$, and the total intake, foraging, hay or milk intake, rectal temperatures, respiration and heart rates and mechanical nonreceptive thresholds (MNTs) in calves were all noted $(p<0.05)$. For the treatment*time interaction, significant differences were showed between the CDNM and CDM groups in the total intake (at $\mathrm{d} 0$ and 1 ), foraging (at $d$ 1), hay or milk intake (at $d 0$ and 1), rectal temperatures (at $24 \mathrm{hr}$ ), heart rates (at 4 and $6 \mathrm{hr}$ ), and MNTs ( right horn at 2, 6, 24, 48 and $72 \mathrm{hr}$; left horn at 6 and $24 \mathrm{hr}$ ); and significant differences were found between the ADNM and ADM groups in the rectal temperatures (at $6 \mathrm{hr}$ ), respiration rates (at 4, 6 and $24 \mathrm{hr}$ ), heart rates (at 2, 4 and $6 \mathrm{hr}$ ), and MNT (right horn at 2 to $72 \mathrm{hr}$, left horn at $24 \mathrm{hr}$ ). Our results indicated that meloxicam relieves pain after calf dehorning and helps restore feed intake.

\section{Introduction}

Meloxicam is a non-steroidal anti-inflammatory drug (NSAID) belonging to the enol-amide group and was developed by the German company Boehringer Ingelheim. Meloxicam selectively inhibits the activity of cyclooxygenase-2 (COX-2) by blocking prostaglandin (PG) synthesis from arachidonic acid (AA) and reducing PG production to achieve antipyretic and analgesic effects. Meloxicam is widely used to control infection and non-infectious inflammation and painful diseases ${ }^{1}$. International veterinary clinical studies report that meloxicam is used for abdominal surgery in dogs ${ }^{2}$, osteoarthritis in cats ${ }^{3}$, delivery in cows ${ }^{4}$, castration in calves ${ }^{5,6}$, and dehorning in calves ${ }^{7-9}$. This drug has shown good analgesic effects and is safe, and a continuous analgesic effect after calf dehorning has been reported.

Dehorning is a routine procedure performed globally in the dairy cattle industry to ensure the safety of dairy cows and breeders and achieve maximum economic benefits ${ }^{10}$. However, consumer interest in animal welfare, especially dehorning, has increased ${ }^{11}$. Amputation, cautery and chemical disbudding in calves are the main dehorning methods in dairy industry ${ }^{12}$. However, all of these methods cause trauma, stress, pain and inflammation in calves, thus violating animal welfare principles ${ }^{13}$. Dehorning is mainly performed with auxiliary local anesthetics and NSAIDs. Local anesthetics relieve acute pain through angular nerve block. NSAIDs inhibit COX-2 expression and block PG synthesis to achieve analgesic effects, effectively relieving chronic pain after surgery. However, the analgesic effect of the commonly used local anesthetic lidocaine lasts only 2-3 hr ${ }^{14,15}$, and the half-lives of ketoprofen, flunixin meglumine and meloxicam are 2-4 hr ${ }^{16}, 6-7 \mathrm{hr}^{17}$, and 26 $\mathrm{hr}^{18,19}$, respectively. Ketoprofen and flunixin meglumine are nonspecific COX inhibitors.

Dehorning benefits the long-term welfare of the animal, but all methods of dehorning cause acute pain and distress, which lead to physiological and behavioral responses. The degree of these responses varies with different dehorning methods. Pain is a subjective state that can only be measured indirectly, and a systematic pain evaluation method has not been developed for cattle after dehorning ${ }^{20}$. Of course, changes in blood physiological indexes, including the concentrations of serum cortisol and haptoglobin ${ }^{21-25}$, plasma substance $P^{26,27}$, prostaglandin $E_{2}{ }^{17,28}$, and whole blood parameters ${ }^{29}$, can be measured. Other physiological indicators, such as heart and respiratory rates $^{7,30,31}$, eye temperature ${ }^{7}$, electroencephalogram results ${ }^{30}$, and the mechanical nonreceptive threshold $(\mathrm{MNT})^{22,32}$, can also be measured. In addition, changes in behavioral indexes, such as head shake, kick, stamp, ear flick, tail flick, walk, stand, lie, head down, eat and drink ${ }^{33-37}$, can be measured. Average daily gain may also be affected by dehorning in calves ${ }^{8,38}$. Nevertheless, further investigations on the elimination of local anesthetics, such as lidocaine or bupivacaine ${ }^{14,15}$, the pain responses in recovered dehorned calves, and potential long-term pain alleviators are needed.

To our knowledge, the effect of meloxicam on the behavior of calves after dehorning have been assessed based on the frequency of each time point, whereas few investigations have focused on postoperative changes in diet and behavior. Moreover, the effects of meloxicam on pain-related behaviors and feed intake after calves undergo chemical disbudding or amputation dehorning with cauterization have not been examined. Therefore, the objective of this study was to assess changes in pain-related behaviors, feed intake, activity levels, physiological indexes and MNTs with different dehorning methods and to estimate the efficacy of s.c. meloxicam administered immediately prior to dehorning in Holstein calves of different ages.

\section{Results}

Based on the measured temperature and humidity, the THls was calculated, and all calves were confirmed to not be in a heat stress environment during the experiment. Clinical examinations showed that all calves were in good health and without serious symptoms, such as death. No calves were eliminated from this study. 


\section{Behaviors}

No significant differences in the frequencies of head shaking, head rubbing, ear flicking, tail flicking and kicking or in the treatment*time interaction were observed between the treatment groups, although significant differences were noted in the frequencies of all behaviors between time points $(p<0.05)$ except for head rubbing and ear flicking (Table 1$)$. In addition, no significant differences in the frequencies of head passing through the fence were observed between treatment groups $(p \geq 0.05)$.

Table 1

The mean $( \pm$ SEM) frequencies of behaviours displayed by calves in treatment groups

\begin{tabular}{|c|c|c|c|c|c|c|c|c|c|c|c|c|}
\hline \multirow[t]{2}{*}{ Behaviour } & \multirow{2}{*}{$\begin{array}{l}\text { Effect } \\
\text { and } p- \\
\text { value }\end{array}$} & \multirow{2}{*}{$\begin{array}{l}\text { ADNM } \\
(n= \\
15)\end{array}$} & \multirow{2}{*}{$\begin{array}{l}\text { ADM } \\
(n= \\
15)\end{array}$} & \multirow{2}{*}{$\begin{array}{l}\text { Std } \\
\text { Error }\end{array}$} & \multicolumn{2}{|l|}{$p$-value } & \multirow{2}{*}{$\begin{array}{l}\text { Effect } \\
\text { and } p- \\
\text { value }\end{array}$} & \multirow{2}{*}{$\begin{array}{l}\text { CDNM } \\
(n= \\
15)\end{array}$} & \multirow{2}{*}{$\begin{array}{l}\text { CDM } \\
(n= \\
15)\end{array}$} & \multirow{2}{*}{$\begin{array}{l}\text { Std } \\
\text { Error }\end{array}$} & \multicolumn{2}{|l|}{ p-value } \\
\hline & & & & & Time & $\begin{array}{l}\text { Tre*Time } \\
\text { a) }\end{array}$ & & & & & Time & Tre*Time \\
\hline $\begin{array}{l}\text { Head } \\
\text { shaking }\end{array}$ & $\begin{array}{l}\text { Treatment } \\
(p= \\
0.618)\end{array}$ & 7.76 & 7.33 & 0.62 & 0.015 & 1 & $\begin{array}{l}\text { Treatment } \\
(p= \\
0.543)\end{array}$ & 7.13 & 6.46 & 0.77 & $<0.001$ & 1 \\
\hline $\begin{array}{l}\text { Head } \\
\text { rubbing }\end{array}$ & $\begin{array}{l}\text { Treatment } \\
(p= \\
0.797)\end{array}$ & 1.79 & 1.69 & 0.26 & 0.302 & 1 & $\begin{array}{l}\text { Treatment } \\
(p= \\
0.495)\end{array}$ & 1.43 & 1.26 & 0.18 & 0.561 & 0.917 \\
\hline $\begin{array}{l}\text { Ear } \\
\text { flicking }\end{array}$ & $\begin{array}{l}\text { Treatment } \\
(p=0.79)\end{array}$ & 8.24 & 7.82 & 1.1 & $<0.001$ & 0.987 & $\begin{array}{l}\text { Treatment } \\
(p=0.53)\end{array}$ & 4.99 & 4.64 & 0.39 & 0.282 & 0.998 \\
\hline $\begin{array}{l}\text { Tail } \\
\text { wagging }\end{array}$ & $\begin{array}{l}\text { Treatment } \\
(p= \\
0.618)\end{array}$ & 19.15 & 16.51 & 3.73 & 0.004 & 0.998 & $\begin{array}{l}\text { Treatment } \\
(p= \\
0.697)\end{array}$ & 13.07 & 11.98 & 1.99 & $<0.001$ & 0.986 \\
\hline $\begin{array}{l}\text { Foot } \\
\text { stamping }\end{array}$ & $\begin{array}{l}\text { Treatment } \\
(p= \\
0.729)\end{array}$ & 5.3 & 4.96 & 0.71 & 0.003 & 1 & $\begin{array}{l}\text { Treatment } \\
(p= \\
0.858)\end{array}$ & 3.62 & 3.54 & 0.32 & $<0.001$ & 0.965 \\
\hline $\begin{array}{l}\text { Head } \\
\text { passing } \\
\text { through } \\
\text { fence }\end{array}$ & $\begin{array}{l}\text { Treatment } \\
(p= \\
0.345)\end{array}$ & 1.4 & 1 & - & - & - & $\begin{array}{l}\text { Treatment } \\
(p= \\
0.806)\end{array}$ & 4.07 & 3.8 & - & - & - \\
\hline
\end{tabular}

\section{Whole condition}

Due to differences in the time points of the activity levels of calves on $d-3,-2,-1,0$, and 1 , the time points at $d-3,-2$ and - 1 were regarded as controls. No significant differences in activity levels in all treatment groups were found for the treatment and treatment*time interaction ( $p$ $\geq 0.05$ ) (Table 2). In addition, significant differences in activity levels were observed between time points ( $<<0.001)$. No significant difference in activity levels were noted between the time points of the controls at $d-3,-2$ and -1 ( $p \geq 0.05$ ), although significant differences compared with $d 0$ and 1 were observed $(p<0.05)$. Additionally, significant differences in activity levels were found between $d 0$ and 1 ( $p<$ 0.05). 
Table 2

The mean $( \pm$ SEM) activity level and total, forage, silage and hay intakes by calves in each treatment group on each day

\begin{tabular}{|c|c|c|c|c|c|c|}
\hline \multirow[t]{2}{*}{ Items } & \multirow[t]{2}{*}{ Group } & \multirow[t]{2}{*}{ Effect and $p$-value } & \multirow[t]{2}{*}{ Mean } & \multirow[t]{2}{*}{ Std Error } & \multicolumn{2}{|c|}{ Effect and p-value } \\
\hline & & & & & Time & Tre $\times$ Time \\
\hline \multirow[t]{4}{*}{ Activity level } & ADNM $(n=15)$ & \multirow{2}{*}{$\begin{array}{l}\text { Treatment } \\
(p=0.27)\end{array}$} & 596.52 & \multirow[t]{2}{*}{32.86} & \multirow[t]{2}{*}{$<0.001$} & \multirow[t]{2}{*}{0.648} \\
\hline & $\operatorname{ADM}(n=15)$ & & 545.09 & & & \\
\hline & CDNM $(n=15)$ & \multirow{2}{*}{$\begin{array}{l}\text { Treatment } \\
(p=0.248)\end{array}$} & 809.53 & \multirow[t]{2}{*}{30.66} & \multirow[t]{2}{*}{$<0.001$} & \multirow[t]{2}{*}{0.623} \\
\hline & CDM $(n=15)$ & & 759.21 & & & \\
\hline \multirow[t]{2}{*}{ Total intake } & ADNM $(n=15)$ & \multirow{2}{*}{$\begin{array}{l}\text { Treatment } \\
(p=0.587)\end{array}$} & 7.21 & \multirow[t]{2}{*}{0.18} & \multirow[t]{2}{*}{$<0.001$} & \multirow[t]{2}{*}{$<0.001$} \\
\hline & $\operatorname{ADM}(\mathrm{n}=15)$ & & 7.07 & & & \\
\hline \multirow[t]{2}{*}{ Forage } & $\operatorname{ADNM}(n=15)$ & \multirow{2}{*}{$\begin{array}{l}\text { Treatment } \\
(p=0.017)\end{array}$} & 1.299 & \multirow[t]{2}{*}{0.03} & \multirow[t]{2}{*}{$<0.001$} & \multirow[t]{2}{*}{$<0.001$} \\
\hline & $\operatorname{ADM}(\mathrm{n}=15)$ & & 1.189 & & & \\
\hline \multirow[t]{2}{*}{ Hay or milk } & ADNM $(n=15)$ & \multirow{2}{*}{$\begin{array}{l}\text { Treatment } \\
(p=0.27)\end{array}$} & 5.92 & \multirow[t]{2}{*}{0.16} & \multirow[t]{2}{*}{$<0.001$} & \multirow[t]{2}{*}{0.004} \\
\hline & $\operatorname{ADM}(n=15)$ & & 5.88 & & & \\
\hline
\end{tabular}

The feed intake of the calves at $d-3,-2,-1,0$, and 1 was recorded by the researchers. No significant differences in total intake, foraging and hay or milk intake were identified for the treatment $(p \geq 0.05)$ except for foraging between the ADNM and ADM groups ( $p<0.05)($ Table 3$)$. Furthermore, significant differences in the total intake, foraging and hay or milk intake were observed between the time points or for the treatment*time interactions $(p<0.05)$. In terms of the treatment*time interaction, significant differences were observed between the CDNM and CDM groups in the total intake at $d 0(p=0.007)$ and $1(p=0.026)$, foraging at $d 1(p=0.002)$, and hay or milk intake at $d 0(p=0.007)$ and $1(p=0.035)$.

Table 3

The mean $( \pm$ SEM) activity level and total, forage, silage and hay intakes by calves in CDNM and CDM group on each day

\begin{tabular}{|c|c|c|c|c|c|c|c|c|c|c|}
\hline \multirow[t]{2}{*}{ Items } & \multirow[t]{2}{*}{ Group } & \multirow[t]{2}{*}{ Effect and $p$-value } & \multirow[t]{2}{*}{ Day -3} & \multirow[t]{2}{*}{ Day -2} & \multirow[t]{2}{*}{ Day -1} & \multirow[t]{2}{*}{ Day 0} & \multirow[t]{2}{*}{ Day 1} & \multirow[t]{2}{*}{ Std Error } & \multicolumn{2}{|c|}{ Effect and p-value } \\
\hline & & & & & & & & & Tre & Time \\
\hline \multirow[t]{4}{*}{ Total intake } & $\mathrm{CDN}$ & Treatment $\times$ Time & 4.7 & 4.64 & 4.82 & $4.36 a$ & $4.54 a$ & \multirow[t]{4}{*}{0.18} & \multirow[t]{4}{*}{0.095} & \multirow[t]{4}{*}{$<0.001$} \\
\hline & $(n=15)$ & $(p<0.001)$ & & & & & & & & \\
\hline & CDM & & 4.87 & 4.89 & 4.93 & $4.85^{b}$ & $4.94^{b}$ & & & \\
\hline & $(n=15)$ & & & & & & & & & \\
\hline \multirow[t]{4}{*}{ Forage } & CDNM & Treatment $\times$ Time & 0.13 & 0.14 & 0.15 & 0.13 & $0.14^{a}$ & \multirow[t]{4}{*}{0.01} & \multirow[t]{4}{*}{0.079} & \multirow[t]{4}{*}{$<0.001$} \\
\hline & $(n=15)$ & $(p<0.001)$ & & & & & & & & \\
\hline & CDM & & 0.14 & 0.16 & 0.16 & 0.15 & $0.18^{b}$ & & & \\
\hline & $(n=15)$ & & & & & & & & & \\
\hline \multirow[t]{4}{*}{ Hay or milk } & CDNM & Treatment $\times$ Time & 4.57 & 4.5 & 4.67 & $4.23^{a}$ & $4.4^{\mathrm{a}}$ & \multirow[t]{4}{*}{0.17} & \multirow[t]{4}{*}{0.1} & \multirow[t]{4}{*}{$<0.001$} \\
\hline & $(n=15)$ & $(p<0.001)$ & & & & & & & & \\
\hline & CDM & & 4.73 & 4.73 & 4.77 & $4.7^{b}$ & $4.77^{\mathrm{b}}$ & & & \\
\hline & \multicolumn{2}{|l|}{$(n=15)$} & & & & & & & & \\
\hline \multicolumn{11}{|c|}{$\begin{array}{l}\text { ADNM, dehorning by amputation without meloxicam; ADM, dehorning by amputation with meloxicam; CDNM, chemical disbudding } \\
\text { without meloxicam; CDM, chemical disbudding with meloxicam. a) Tre = Treatment. }{ }^{a, b} \text { The values for two groups (ADNM and ADM, } \\
\text { CDNM and CDM) with different superscripts differ significantly at } p<0.05 \text {. }\end{array}$} \\
\hline
\end{tabular}




\section{Physiology}

The time of dehorning was designated $0 \mathrm{hr}$. Regarding the respiration and heart rates of calves from - 24 to $24 \mathrm{hr}$ (Fig. 1), significant differences between treatments and time or for the treatment*time interactions were observed between the ADNM and ADM groups( $p<0.05)$. Moreover, a significant difference in the rectal temperatures and respiration and heart rates of calves was only identified for time points between all treatment groups. In terms of the treatment*time interaction, significant differences were observed between the ADNM and ADM groups in rectal temperatures at $6 \mathrm{hr}(\mathrm{p}=0.002)$, respiration rates at $4 \mathrm{hr}(\mathrm{p}=0.006), 6 \mathrm{hr}(\mathrm{p}=0.015)$ and $24 \mathrm{hr}(\mathrm{p}=0.002)$, and heart rates at $4 \mathrm{hr}(\mathrm{p}=0.013), 6 \mathrm{hr}(\mathrm{p}=0.001)$ and $24 \mathrm{hr}(\mathrm{p}=0.032)$. In addition, significant differences in rectal temperatures at $24 \mathrm{hr}(\mathrm{p}=0.022)$ and heart rates at $6 \mathrm{hr}(\mathrm{p}=0.048)$ and $24 \mathrm{hr}(\mathrm{p}=0.034)$ were found between the CDNM and CDM groups.

\section{MNT}

Due to differences in the time points of MNTs in calves from - 72 to $72 \mathrm{hr}$, the MNTs of the left horn (LH) and right horn (RH) between all treatment groups were significantly different based on the treatment, time or treatment*time interactions $(p<0.05)$, although the MNTs of the LH between the CDNM and CDM groups only showed a significant difference for time points $(p<0.05)$. This difference is further illustrated in Fig. 2, which displays the MNT versus time in all treatment groups. In terms of the treatment*time interaction, significant differences were observed between the ADNM and ADM groups in the MNTs of the RH at - $72 \mathrm{hr}(\mathrm{p}=0.043),-24 \mathrm{hr}(\mathrm{p}=0.016), 2 \mathrm{hr}(\mathrm{p}=0.049), 6 \mathrm{hr}(\mathrm{p}<$ $0.001), 24 \mathrm{hr}(\mathrm{p}<0.001), 48 \mathrm{hr}(\mathrm{p}<0.001)$ and $72 \mathrm{hr}(\mathrm{p}<0.001)$; the MNTs of the LH at $-48 \mathrm{hr}(\mathrm{p}=0.02), 6 \mathrm{hr}(\mathrm{p}<0.001)$ and $24 \mathrm{hr}(\mathrm{p}=$ 0.001). Significant differences were also observed between the CDNM and CDM groups in MNTs of the RH at $2 \mathrm{hr}(\mathrm{p}=0.002), 4 \mathrm{hr}(\mathrm{p}=$ $0.001), 6 \mathrm{hr}(\mathrm{p}<0.001), 24 \mathrm{hr}(\mathrm{p}<0.001), 48 \mathrm{hr}(\mathrm{p}<0.001)$ and $72 \mathrm{hr}(\mathrm{p}=0.01)$; and the MNTs of the LH at $24 \mathrm{hr}(\mathrm{p}=0.003)$. The measurement location had an effect on pain sensitivity $(p<0.05)$ after the experiment (Table 4$)$. In addition, the different treatments had an effect on pain sensitivity at all locations $(p<0.05)$. Location 2 was the most sensitive compared with locations 1,3 and $4(p<0.05)$.

Table 4

The mean ( \pm SEM) MNT at each location around the horn buds

\begin{tabular}{|c|c|c|c|c|c|c|c|c|}
\hline \multirow[t]{2}{*}{ Location } & \multicolumn{2}{|l|}{ ADNM } & \multicolumn{2}{|l|}{ ADM } & \multicolumn{2}{|l|}{ CDNM } & \multicolumn{2}{|l|}{ CDM } \\
\hline & $\begin{array}{l}\left.\text { Shama }^{a}\right) \\
(n=210)\end{array}$ & $\begin{array}{l}\left.\text { Dehorning }^{b}\right) \\
(n=180)\end{array}$ & $\begin{array}{l}\text { Sham } \\
(n=210)\end{array}$ & $\begin{array}{l}\text { Dehorning } \\
(n=180)\end{array}$ & $\begin{array}{l}\text { Sham } \\
(n=210)\end{array}$ & $\begin{array}{l}\text { Dehorning } \\
(n=180)\end{array}$ & $\begin{array}{l}\text { Sham } \\
(n=210)\end{array}$ & $\begin{array}{l}\text { Dehorning } \\
(n=180)\end{array}$ \\
\hline 1 & $1.6 \pm 0.02^{a B}$ & $0.94 \pm 0.03^{\mathrm{cB}}$ & $1.63 \pm 0.02^{\mathrm{aB}}$ & $1.13 \pm 0.03^{\mathrm{bB}}$ & $1.22 \pm 0.01^{\mathrm{aB}}$ & $0.8 \pm 0.02^{c B}$ & $1.19 \pm 0.01^{\mathrm{aB}}$ & $0.89 \pm 0.02^{b B}$ \\
\hline 2 & $1.29 \pm 0.01^{\mathrm{aA}}$ & $0.77 \pm 0.03^{\mathrm{cA}}$ & $1.33 \pm 0.02^{\mathrm{aA}}$ & $0.91 \pm 0.03^{\mathrm{bA}}$ & $0.99 \pm 0.01^{\mathrm{ac}}$ & $0.64 \pm 0.02^{\mathrm{cA}}$ & $0.98 \pm 0.01^{\mathrm{aC}}$ & $0.73 \pm 0.02^{b A}$ \\
\hline 3 & $1.61 \pm 0.02^{\mathrm{aB}}$ & $0.97 \pm 0.03^{c B}$ & $1.65 \pm 0.02^{\mathrm{aBC}}$ & $1.14 \pm 0.04^{\mathrm{bB}}$ & $1.21 \pm 0.01^{\mathrm{aB}}$ & $0.8 \pm 0.02^{\mathrm{cB}}$ & $1.2 \pm 0.01^{\mathrm{aB}}$ & $0.89 \pm 0.02^{b B}$ \\
\hline 4 & $1.65 \pm 0.02^{a B}$ & $0.97 \pm 0.03^{c B}$ & $1.69 \pm 0.02^{\mathrm{aC}}$ & $1.18 \pm 0.04^{\mathrm{bB}}$ & $1.25 \pm 0.01^{\mathrm{aA}}$ & $0.83 \pm 0.02^{\mathrm{cB}}$ & $1.24 \pm 0.01^{\mathrm{aA}}$ & $0.9 \pm 0.02^{\mathrm{bB}}$ \\
\hline \multicolumn{9}{|c|}{$\begin{array}{l}\text { ADNM = dehorning by amputation without meloxicam; } A D M=\text { dehorning by amputation with meloxicam; } C D N M=\text { chemical disbudding } \\
\text { without meloxicam; CDM = chemical disbudding with meloxicam. a) Sham: time before dehorning }(-72 \text { to } 0 \text { hr); } b) \text { Dehorning: time after } \\
\text { AD or CD ( } 2 \text { to } 72 \mathrm{hr}) \text {. A,B,C The values within a row with different superscripts differ significantly at } p<0.05 \text {. a,b The values of the } \\
\text { treatment groups (ADNM and ADM, CDNM and CDM) within a column with different superscripts differ significantly at } p<0.05 \text {. }\end{array}$} \\
\hline
\end{tabular}

\section{Discussion}

The objectives of the present study were to examine the effect of meloxicam on calves considering physiological, behavioral, feed intake and pain sensitivity indexes. Calves underwent two dehorning methods: CD or dehorning by amputation with vascular cauterization. CD in calves is now common in China because it is simple, convenient, and affordable for farmers, although there is currently little research on this method. By simulating false dehorning, the stress response caused by actual dehorning can be eliminated to a certain extent. The calves in the control group were also included in the treatment group to exclude the effects of individual differences. The administration of saline in this experiment was injected in exactly the same way in the same sites and with the same volume as meloxicam and served as the 'control' to evaluate the impact of the sham operation and eliminate the effect of the injection itself. Therefore, the following discussion will focus on 
the changes in physiology, behavior, feed intake, and pain sensitivity associated with meloxicam administration before and after calf dehorning to determine its analgesic effect.

An interesting phenomenon is the apparent circadian pattern of pain-related behaviors ${ }^{32}$, which appear to occur less frequently early in the day, frequently from mid-afternoon until evening feeding, and then less frequently thereafter. Therefore, the frequencies of behaviors displayed by calves in each treatment group on $\mathrm{d}-1,0$, and 1 included the frequencies of behaviors observed at 7:00 am, 12:00 pm and 7:00 $\mathrm{pm}$. The purpose was to explore the effects of meloxicam on feed intake and pain-related behaviors during feeding in dehorned calves. Recent research has found that meloxicam-treated, dehorned, 6- to 12-week-old Holstein calves displayed less ear flicking for 44 hr and head shaking for $9 \mathrm{hr}$ after dehorning than calves not treated with meloxicam ${ }^{32}$; moreover, meloxicam significantly increased the time spent eating following castration and/or dehorning in 3-month-old Holstein calves ${ }^{29}$. In another study, meloxicam significantly reduced the head turning frequency and increased weight gain following castration and dehorning in 6- to 8-month-old beef calves ${ }^{37}$, although clear observations of the effects of meloxicam on other behaviors displayed by 6- to 8-mo-old dehorned beef calves have not been reported ${ }^{9}$. Overall, the changes in behavior suggested that meloxicam was effective in reducing post-surgical pain and distress associated with calf dehorning. This experiment indicated that the pain relief process after calf dehorning is not associated with the analgesic effect of meloxicam and may be closely related to hunger. In addition, changes in behaviors caused by dehorning were not clearly observed, which may be because behavior was observed only during feeding and starvation may cause calves to ignore pain for a short time. The total intake, forage, silage and hay and milk intakes in all groups were different after dehorning, which may be due to pain intensity caused by differences in the dehorning methods and tolerance levels due to differences in calf ages. This experiment indicated that meloxicam promoted the resumption of intake in 1- to 3-wk-old calves, which may be because milk is easier for calves to consume. Thus, meloxicam can effectively relieve pain in 1- to 3-wkold calves after CD and promote feed intake recovery.

Currently, most studies have explored walking time to describe the relationship between calf activity levels and pain. Studies have found that ketoprofen ${ }^{38}$, lignocaine ${ }^{36}$, and meloxicam had no effect on walking time after calf dehorning, and even meloxicam caused a significant increase in walking time ${ }^{37}$. Therefore, it is feasible to use mobile phone software to observe data from a pedometer attached to the right hind leg of calves to record daily activity levels. In the present study, there were significant differences in the activity levels of calves in all groups after dehorning $(p \leq 0.05)$ but no significant difference between the treatment groups $(p>0.05)$, indicating that the change could have been caused by dehorning; however, meloxicam did not show an obvious analgesic effect. The activity level of calves before dehorning was clearly higher than that after dehorning, suggesting that postoperative pain existed. Generally, the activity level in the ADM and CDM groups decreased more than that in the ADNM and CDNM groups, respectively. In addition, the average activity levels in the CDNM and CDM groups were higher than those in the ADNM and ADM groups, which may have been caused by fear associated with the age differences in the calves and different pain levels caused by the different dehorning methods. Thus, meloxicam may promote a certain pain relief effect by potentially reducing the postoperative activity level.

Dehorning can cause traumatic stress, pain and local inflammation and affect a calf's normal physiological parameters, including rectal temperature and respiration and heart rates. Previous research mostly focused on the effect of meloxicam on the physiological condition of calves following cautery disbudding, and the results suggested that meloxicam reduces the respiratory rate, heart rate, and heart rate variability 7,23 but not the eye temperature ${ }^{39}$. The heart rate was significantly reduced by the combination of xylazine, although orphanol and bupivacaine ${ }^{31}$. Moreover, local inflammation can cause fever. The relationship between rectal temperature and meloxicam in calves following dehorning has not been previously reported. In the present study, significant differences were not observed in rectal temperature or respiration and heart rates before dehorning between the treatment groups $(p>0.05)$. In addition, all the treatment groups showed an overall increasing trend followed by a decreasing trend after dehorning. The effective time and efficacy of meloxicam were significantly different between the ADNM and ADM groups. In general, meloxicam can significantly reduce the rectal temperature and respiration and heart rates of calves undergoing dehorning relative to other methods of relieving postoperative pain.

A pressure algometer is effective for evaluating the effects of analgesics on dehorning pain and can determine the minimum amount of pressure required to elicit a pain response ${ }^{32}$. Meloxicam has been reported to increase the MNTs of the LH and RH in calves after dehorning, indicating that meloxicam can alleviate pain to some extent ${ }^{22,39}$. Therefore, it is necessary to handle calves in advance to adapt them to the operational procedures to avoid errors as much as possible. In the present study, all calves showed significantly decreased tolerance to pressure following dehorning. The effect of meloxicam on the MNT measured by the algometer was observed. However, the MNTs of the LH and $\mathrm{RH}$ in calves were significantly different. Between the ADNM and ADM groups, the MNTs of the LH after dehorning did not indicate the same efficacy of meloxicam efficacy as observed for the $\mathrm{RH}$, and between the CDNM and CDM groups, the MNTs of the RH after dehorning more obviously indicated the efficacy of meloxicam efficacy relative to those of the LH. However, the MNTs of the LH and RH before dehorning did not show obvious differences in all groups. When using a pressure algometer to detect the MNT value of the horns, the RH precedes the $\mathrm{LH}$; thus, because the pain caused by the pressure algometer induces fear in the calf, more obvious evasive psychology is

Page $7 / 18$ 
observed when detecting the MNTs of the LH. In addition, there were significant effects on the mean MNTs according to the measurement sites (1-4) in the LH and RH before and after dehorning. Location 2 was the most sensitive compared with locations 1,3 , and 4 ( $p<0.05$ ), which is in accordance with research by Heinrich et al. ${ }^{23}$ Since local anesthetic was not used to block the cornual nerve, the MNT at 2 hr decreased dramatically after calf dehorning, which is consistent with the results of Allen et al. ${ }^{39}$, who used a local anesthetic. However, the average value of the MNT was slightly different from those in other related reports ${ }^{23,32,39}$, which may be attributable to differences in toleration according to the ages of the calves. Similarly, the pressure algometer used in this experiment contained a round iron tip instead of a round rubber tip, which may have caused discomfort at the sites of the wounds. With increasing time intervals and measurement times, the MNT of each measurement in the LH and RH will be affected by the interactions between the calves and experimenters, especially in 1- and 3wk-old calves. Overall, this finding indicates that meloxicam can relieve pain after calf dehorning.

Most previous studies explored the analgesic effects of meloxicam in calves with different ages, calves receiving different routes of administration and calves undergoing different dehorning methods. Dehorning by amputation is highly invasive and stressful and produces greater pain than cautery disbudding due to extensive damage to the horns. CD has the following advantages: it is simple, convenient, and affordable for farmers; causes less damage to horns; and causes less pain in calves than amputation. However, limited research is available on this method. The purpose of this study was to explore the analgesic effect of meloxicam alone in calves of different ages undergoing different methods of dehorning, and we found that meloxicam can relieve pain and promote the recovery of feed intake after calf dehorning. Thus, performing CD in 1- to 3-wk-old calves is beneficial.

In conclusion, the feed intake and behavior during feeding displayed by calves can reflect pain and tolerance at that point in time. Remotely observing a calf's daily activity with a pedometer can directly reflect the degree of pain better than walking time. Meloxicam effectively alleviated the pain caused by CD in 1-to 3-wk-old calves, and the effect was more obvious than that in 1.5- to 6-mo-old calves following dehorning by amputation. Therefore, meloxicam is recommended to relieve pain caused by CD. Although research is still scarce, meloxicam should still be recommended to farmers.

\section{Methods}

All experimental procedures were approved by the Sichuan Agricultural University College of Veterinary Medicine before the initiation of the study. All animal operations and procedures were conducted according to the approved guidelines and were in accordance with the international Guide for the Care and Use of Laboratory Animals.

\section{Animals, experimental design and treatments}

The study was conducted in 60 Holstein calves from a dairy farm in Qionglai, Sichuan, China. At 1.5 to 6 months of age, Holstein calves ( $\mathrm{n}=$ 30) weighing $148 \pm 32.68 \mathrm{~kg}$ were allotted to pens measuring $30.0 \times 4.9 \mathrm{~m}$ (15 calves/pen), and hay, water and maize silage were provided daily. At 1 to 3 weeks of age, Holstein calves $(n=30)$ weighing $51.27 \pm 5.97 \mathrm{~kg}$ were allotted to pens measuring $10.0 \times 6.5 \mathrm{~m}(15 \mathrm{calves} / \mathrm{pen})$. The calves were fed milk without antibiotics twice daily, and small amounts of maize silage and hay were provided daily. All calves underwent clinical examination 4 days (d) prior to the official start of the trial and were included in the study sample if they were determined to be healthy. In addition, the daily feed intake was calculated by calculating the total feed intake of all calves in the first 4 days. Based on this condition, the quantity of feed offered was adjusted daily to obtain daily leftovers of 5 to $10 \%$ of the total amount provided in order to ensure random intake.

The experiment consisted of a $2 \times 2$ factorial design where the main factors included the dehorning method and medication treatment. The two dehorning methods and two medication treatments were as follows:

1) Dehorning by amputation (AD): physical dehorning was performed using Barnes dehorners and electrocauterization was performed at 600 ${ }^{\circ} \mathrm{C}$ for approximately 15 - $30 \mathrm{sec}$ to control any hemorrhaging. The treatment was applied to calves at 3-6 months of age.

2) Chemical disbudding (CD): sodium hydroxide ointment in an amount equal to the area of approximately 5 coins was evenly applied to each bud. The treatment was applied to calves at 1-3 weeks of age.

3) Saline (NM): calves received a single subcutaneous injection of $0.5 \mathrm{mg} / \mathrm{kg}$ of saline (saline, Gansu Xintianma Pharmaceutical Co., Ltd.) 10 min before $A D$ or $C D$.

4) Meloxicam (M): calves received a single subcutaneous injection of $0.5 \mathrm{mg} / \mathrm{kg}$ of meloxicam (Metacam $20 \mathrm{mg} / \mathrm{ml}$, Labiana Life Sciences S.A, Import Drug Registration NO: (2016) WaiShou YaoZhengZi No.19) 10 min before AD or CD. 
The calves were divided into 4 groups, equally distributed by weight into pens and randomly assigned to treatments. Over a period of $7 \mathrm{~d}$, the four pens of calves were treated with their respective treatments on each day. Calves were restrained in a squeeze chute to perform all treatments. In all calves, both horns were desensitized using a cornual nerve block at least 10 min prior to dehorning by injecting $5 \mathrm{ml}$ (100 $\mathrm{mg}$ ) of $20 \mathrm{mg} / \mathrm{ml}$ Lidocaine (Lidocaine Hydrochloride Injection; Shandong Hualu Pharmaceutical Co., Ltd) to a depth of approximately $1 \mathrm{~cm}$ under the temporal ridge around each cornual nerve. Treatments included the following: (1) ADNM ( $n=15) ;(2)$ ADM ( $n=15) ;(3)$ CDNM ( $n=$ 15); and (4) CDM $(n=15)$. In all calves the horn bud was prepared first by shaving the hair around the site using electric clippers. All calves underwent a simulated dehorning procedure on $\mathrm{d}-1$ without medication injection, electrocautery or sodium hydroxide ointment application. The simulated dehorning procedure is consistent with the true dehorning process, the test indicators are the same and the time points correspond to each other. The purpose of a simulated dehorning procedure is to eliminate the stress response caused by the experimenter's operation and ensure the accuracy of the test indicators. To keep flies away, the dehorning wounds were sprayed with $0.5 \%$ permethrin.

\section{Behavior data collection}

The measured behaviors of calves included "head shaking, head rubbing, ear flicking, tail flicking, kicking and head passing through the fence" (Table 5). To encourage the calves to adapt to the experimenters and ensure that the experimenters could skillfully and accurately record various behavioral frequencies, a simulation of behavioral frequencies was carried out 3 days before the formal test. When the calves ate or drank at 7:00 am, 12:00 pm and 7:00 pm on d -1, 0 and 1 as usual, four trained experimenters recorded the behavior frequencies of the calves at 9 time points. The feeding process of calves can be fully guaranteed by 10 min of behavioral frequency measurement time.

Table 5

Description of behaviours

\begin{tabular}{|ll|}
\hline $\begin{array}{l}\text { Behaviour } \\
\text { (frequency) }\end{array}$ & Description \\
\hline $\begin{array}{l}\text { Head shaking } \\
\text { Head rubbing }\end{array}$ & Repeated movement of the head from side to side in a rapid motion. \\
\hline Ear flicking & Repeated movement of one or both ears in a quick motion independent of head shaking. \\
\hline $\begin{array}{l}\text { Tail flicking } \\
\text { Kicking }\end{array}$ & Lovement of the tail vertically. \\
\hline $\begin{array}{l}\text { Head passing } \\
\text { through fence }\end{array}$ & $\begin{array}{l}\text { Inserting the head through the bars of the pen towards the food and water buckets. This behaviour was recorded at } \\
\text { feeding time at only } 6 \text { hr following dehorning. }\end{array}$ \\
\hline a) Points are behaviours without a measurable duration and are quantified by the frequency.
\end{tabular}

\section{Whole condition data collection}

Whole conditions measured included feed intake and activity level. The researchers observed and recorded the activity level and feed intake of calves on $d-3,-2,-1,0$, and 1 . The feed intake of all calves was the same as usual three days before the formal test. In addition, all calves wore pedometers three days before the experiment to ensure that the adaptive stress response of the calves was eliminated. The experimenters attached a pedometer (Huawei e3 pedometer, Huawei Technology Co., Ltd.) to the tarsal joint of each calf's right hind leg to monitor daily activity levels with a mobile phone. The Huawei e3 pedometer uses an extremely sensitive three-axis acceleration electronic shock sensor combined with built-in software to output steps and has no special requirements for placement position and direction. The temperature and humidity were measured with a thermo-hygrometer (Deli 9010 In-outdoor Thermo-hygrometer, Deli Group Co., Ltd.) at 7:00 am, 12:00 pm and 7:00 pm daily. Furthermore, the experimenters recorded the daily intake of all calves and weighed them at 6:00 am on d 0. The experiment schedule was adjusted according to temperature-humidity indexes (THIs), and the calves with poor health were eliminated by clinical diagnosis.

\section{Physiological data collection}


Dehorning can affect the physiological status of calves. Three researchers participated in the collection of physiological data from all calves and observed the respiration rates, heart rates and rectal temperatures of calves at $-24 \mathrm{hr},-6 \mathrm{hr},-4 \mathrm{hr},-2 \mathrm{hr}, 0 \mathrm{hr}, 2 \mathrm{hr}, 4 \mathrm{hr}, 6 \mathrm{hr}$, and $24 \mathrm{hr}$ with a stethoscope (multifunctional stethoscope, JiangSu YuWell Medical Equipment Co., Ltd.) and a thermometer (soft head electronic thermometer BT-A21G, Dongguan Fudakang Industry Co., Ltd.).

\section{Pressure algometry}

Pain sensitivity was measured at $-72 \mathrm{hr},-48 \mathrm{hr},-24 \mathrm{hr},-6 \mathrm{hr},-4 \mathrm{hr},-2 \mathrm{hr}, 0 \mathrm{hr}, 2 \mathrm{hr}, 4 \mathrm{hr}, 6 \mathrm{hr}, 24 \mathrm{hr}, 48 \mathrm{hr}$, and $72 \mathrm{hr}$ for the sham and actual dehorning groups using a pressure algometer (Digital Force Gauge SL-30, Dongguan Jingyou Mould Hardware Co., Ltd.), and the same trained researcher performed all measurements (Fig. 3). The device was equipped with a round iron tip measuring $1 \mathrm{~cm}$ in diameter. The amount of pressure that a calf tolerated was measured in kilograms of force $(\mathrm{kgf})$ and considered the mechanical nonreceptive threshold.

\section{Statistical analysis}

All data were analyzed using IBM SPSS statistics 21. GraphPad Prism software (Version 8.02; GraphPad Software Inc., San Diego, CA, USA) was used for graph plotting of the experimental data. The data on passing a head through a fence between treatment groups were analyzed by Wilcoxon rank sum test. Furthermore, the MNTs at each location surrounding the horn buds before and after the operation were compared by a one-way analysis of variance (ANOVA), and the other data were analyzed by a generalized linear mixed model (GLMM). The treatment, time, and treatment*time interaction were used as fixed effects, whereas calf was the subject of the repeated measures. Data are presented as the mean \pm SEM. For all statistical calculations, $p$ values $<0.05$ were considered statistically significant.

\section{Declarations}

\section{Data availability}

The data used to support the findings of this study are available from the corresponding author upon request.

\section{Acknowledgments}

The study was supported by the Sichuan beef cattle innovation team of National Modern Agricultural Industry Technology System (SCCXTD2020-13); National Key Research and Development Project (No.2018YFD0501800); and Sichuan Science and Technology Program (No.2018NZ0002, NO.2019YFQ0012). We would like to thank AJE (www.aje.cn) for performing English language editing.

\section{Author contributions}

Z.Q.L., Y.L.Z. and Y.C.C. were the principal investigator and interpretation of the findings and wrote the manuscript. D.J.C., J.F. and Y.X. contributed to manuscript modification. Z.C.Z. and Z.S.W. contributed to the study design. T.Y.T., H.M.C., Y.G., X.P.M., L.P.G., J.C.Q., Y.C.H., J.Y. and W.W. contributed to the subject briefings and data collection. H.R.G., S.Y.C., G.Y., Z.J.Z., Z.H.R., M.Z., Y.W., J.L.D., S.M.Y., S.Z.C. and H.W.Z. contributed to carried out data analyses. All authors read and approved the final version of the manuscript.

\section{Competing interests}

The author(s) declare no competing interests.

\section{References}

1. Hawkey, C. J. COX-2 inhibitors. Lancet 353, 307-314 (1999).

2. Mathews, K. A., Pettifer, G., Foster, R. \& McDonell, W. Safety and efficacy of preoperative administration of meloxicam, compared with that of ketoprofen and butorphanol in dogs undergoing abdominal surgery. Am. J. Vet. Res. 62, 882-888 (2001).

3. Monteiro, B. P. et al. Analgesic efficacy of an oral transmucosal spray formulation of meloxicam alone or in combination with tramadol in cats with naturally occurring osteoarthritis. Vet. Anaesth. Analg. 43, 643-651 (2016). 
4. Mainau, E., Cuevas, A., Ruiz-de-la-Torre, J. L., Abbeloos, E. \& Manteca, X. Effect of meloxicam administration after calving on milk production, acute phase proteins, and behavior in dairy cows. J. Vet. Behav. 9, 357-363 (2014).

5. Meléndez, D. M. et al. Effect of a single dose of meloxicam prior to band or knife castration in 1-wk-old beef calves: I. Acute pain. J. Anim. Sci. 96, 1268-1280 (2018).

6. Meléndez, D. M. et al. Effect of subcutaneous meloxicam on indicators of acute pain and distress after castration and branding in 2-moold beef calves. J. Anim. Sci. 96, 3606-3621 (2018).

7. Stewart, M. et al. Effects of local anesthetic and a nonsteroidal antiinflammatory drug on pain responses of dairy calves to hot-iron dehorning. J. Dairy Sci. 92, 1512-1519 (2009).

8. Tucker, C. B. et al. Pain sensitivity and healing of hot-iron cattle brands. J. Anim. Sci. 92, 5674-5682 (2014).

9. van der Saag, D., Lomax, S., Windsor, P. A., Taylor, C. \& White, P. J. Evaluating treatments with topical anaesthetic and buccal meloxicam for pain and inflammation caused by amputation dehorning of calves. PLoS One 13, e0198808 (2018).

10. Stafford, K. J. \& Mellor, D. J. Addressing the pain associated with disbudding and dehorning in cattle. Appl. Anim. Behav. Sci. 135, 226231 (2011).

11. Rollin, B. E. Annual meeting keynote address: animal agriculture and emerging social ethics for animals. J. Anim. Sci. 82, 955-964 (2004).

12. Stafford, K. J. \& Mellor, D. J. Dehorning and disbudding distress and its alleviation in calves. Vet. J. 169, 337-349 (2005).

13. American Veterinary Medical Association. Backgrounder: welfare implications of the dehorning and disbudding of cattle. http://www.avma.org/reference/backgrounders/dehorning_cattle_bgnd.asp (2012).

14. McMeekan, C. M. et al. Effects of local anaesthesia of 4 to 8 hours duration on the acute cortisol response to scoop dehorning in calves. Aust. Vet. J. 76, 281-285 (1998).

15. Petrie, N. J., Mellor, D. J., Stafford, K. J., Bruce, R. A. \& Ward, R. N. Cortisol responses of calves to two methods of disbudding used with or without local anaesthetic. N. Z. Vet. J. 44, 9-14 (1996).

16. Landoni, M. F., Cunningham, F. M. \& Lees, P. Pharmacokinetics and pharmacodynamics of ketoprofen in calves applying PK/PD modelling. J. Vet. Pharmacol. Ther. 18, 315-324 (1995).

17. Fraccaro, E. et al. A study to compare circulating flunixin, meloxicam and gabapentin concentrations with prostaglandin E2 levels in calves undergoing dehorning. Res. Vet. Sci. 95, 204-211 (2013).

18. Coetzee, J. F., KuKanich, B., Mosher, R. \& Allen, P. S. Pharmacokinetics of intravenous and oral meloxicam in ruminant calves. Vet. Ther. 10, E1-E8 (2009).

19. European Agency for the Evaluation of Medicinal Products (EMEA). Veterinary medicine European public assessment report (EPAR): metacam. https://www.ema.europa.eu/en/medicines/veterinary/EPAR/metacam (2018).

20. Smith, E. R. \& Modric, S. Regulatory considerations for the approval of analgesic drugs for cattle in the United States. Vet. Clin. N. Am.: Food Anim. Pract. 29, 1-10 (2013).

21. Ballou, M. A. et al. Administration of anesthetic and analgesic prevent the suppression of many leukocyte responses following surgical castration and physical dehorning. Vet. Immunol. Immunopathol. 151, 285-293 (2013).

22. Glynn, H. D. et al. The pharmacokinetics and effects of meloxicam, gabapentin, and flunixin in postweaning dairy calves following dehorning with local anesthesia. J. Vet. Pharmacol. Ther. 36, 550-561 (2013).

23. Heinrich, A., Duffield, T. F., Lissemore, K. D., Squires, E. J. \& Millman, S. T. The impact of meloxicam on postsurgical stress associated with cautery dehorning. J. Dairy Sci. 92, 540-547 (2009).

24. Sutherland, M. A. et al. Cortisol responses to dehorning of calves given a 5-h local anaesthetic regimen plus phenylbutazone, ketoprofen, or adrenocorticotropic hormone prior to dehorning. Res. Vet. Sci. 73, 115-123 (2002).

25. Stafford, K. J., Mellor, D. J., Todd, S. E., Ward, R. N. \& McMeekan, C. M. The effect of different combinations of lignocaine, ketoprofen, xylazine and tolazoline on the acute cortisol response to dehorning in calves. N. Z. Vet. J. 51, 219-226 (2003).

26. Coetzee, J. F. et al. Plasma concentrations of substance P and cortisol in beef calves after castration or simulated castration. Am. J. Vet. Res. 69, 751-762 (2008).

27. Coetzee, J. F. et al. Pharmacokinetics and effect of intravenous meloxicam in weaned Holstein calves following scoop dehorning without local anesthesia. BMC Vet. Res. 8, 153 (2012).

28. Kleinhenz, M. D. et al. The impact of pain on the pharmacokinetics of transdermal flunixin meglumine administered at the time of cautery dehorning in Holstein calves. Vet. Anaesth. Analg. 45, 849-857 (2018). 
29. Sutherland, M. A., Ballou, M. A., Davis, B. L. \& Brooks, T. A. Effect of castration and dehorning singularly or combined on the behavior and physiology of Holstein calves. J. Anim. Sci. 91, 935-942 (2013).

30. Gibson, T. J., Johnson, C. B., Stafford, K. J., Mitchinson, S. L. \& Mellor, D. J. Validation of the acute electroencephalographic responses of calves to noxious stimulus with scoop dehorning. N. Z. Vet. J. 55, 152-157 (2007).

31. Grøndahl-Nielsen, C., Simonsen, H. B., Lund, J. D. \& Hesselholt, M. Behavioural, endocrine and cardiac responses in young calves undergoing dehorning without and with use of sedation and analgesia. Vet. J. 158, 14-20 (1999).

32. Heinrich, A., Duffield, T. F., Lissemore, K. D. \& Millman, S. T. The effect of meloxicam on behavior and pain sensitivity of dairy calves following cautery dehorning with a local anesthetic. J. Dairy Sci. 93, 2450-2457 (2010).

33. Doherty, T. J. et al. Effects of a concentrated lidocaine solution on the acute phase stress response to dehorning in dairy calves. J. Dairy Sci. 90, 4232-4239 (2007).

34. McMeekan, C. et al. Effects of a local anaesthetic and a non-steroidal anti-inflammatlory analgesic on the behavioural responses of calves to dehorning. N. Z. Vet. J. 47, 92-96 (1999).

35. Milligan, B. N., Duffield, T. \& Lissemore, K. The utility of ketoprofen for alleviating pain following dehorning in young dairy calves. Can. Vet. J. 45, 140-143 (2004).

36. Sylvester, S. P., Stafford, K. J., Mellor, D. J., Bruce, R. A. \& Ward, R. N. Behavioural responses of calves to amputation dehorning with and without local anaesthesia. Aust. Vet. J. 82, 697-700 (2004).

37. van der Saag, D. et al. Effects of topical anaesthetic and buccal meloxicam treatments on concurrent castration and dehorning of beef calves. Animals 8, 35 (2018).

38. Faulkner, P. M. \& Weary, D. M. Reducing pain after dehorning in dairy calves. J. Dairy Sci. 83, $2037-2041$ (2000).

39. Allen, K. A. et al. The effect of timing of oral meloxicam administration on physiological responses in calves after cautery dehorning with local anesthesia. J. Dairy Sci. 96, 5194-5205 (2013).

\section{Figures}


A

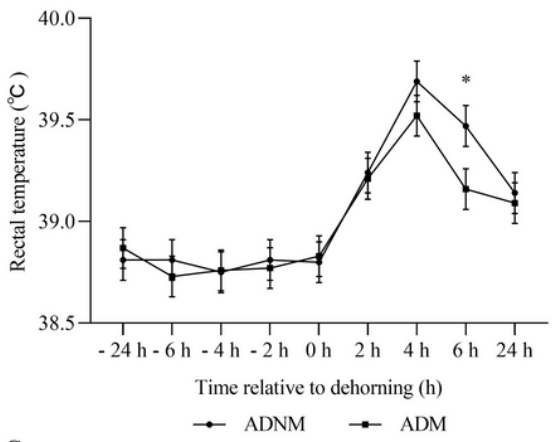

C

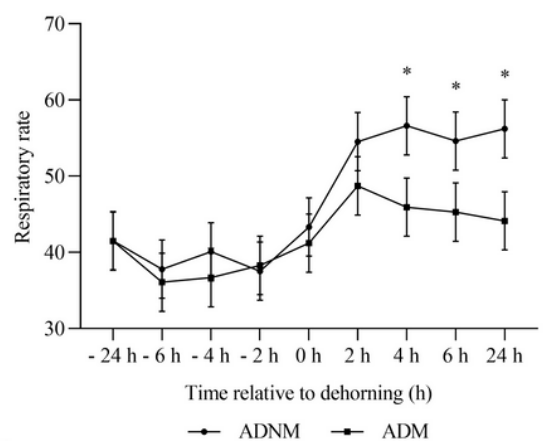

E

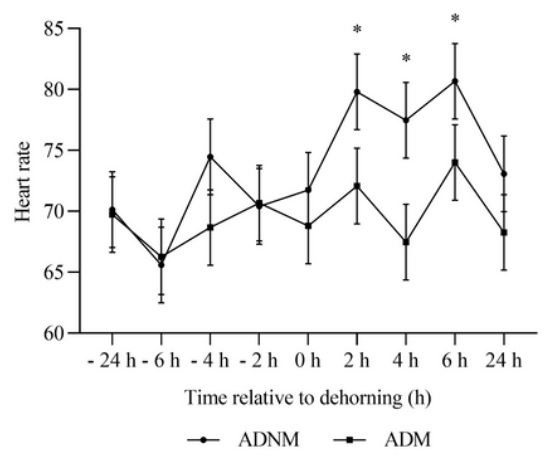

B
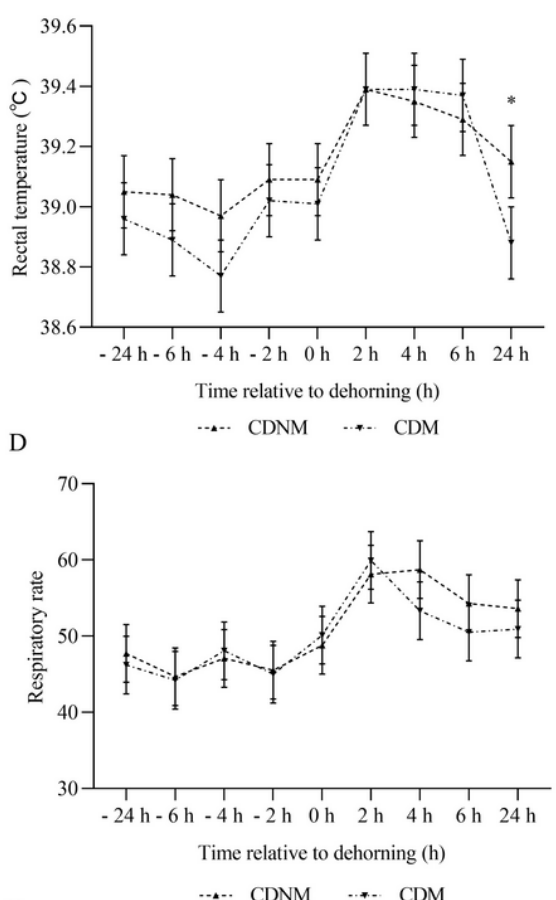

F

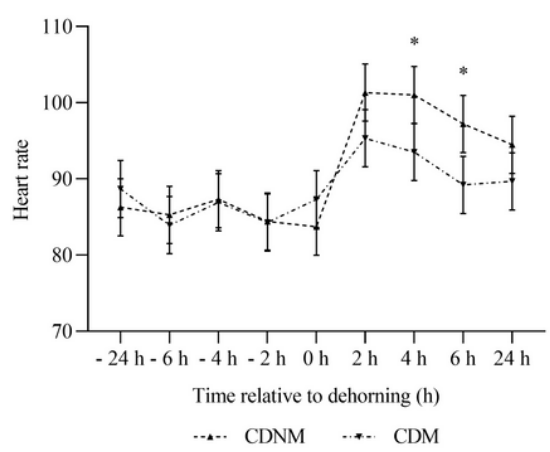

\section{Figure 1}

All data about Rectal Temperatures and Respiration and Heart Rates from -24 to $24 \mathrm{hr}$ of calves. (A) Rectal Temperatures of ADNM and ADM groups. (B) Rectal Temperatures of CDNM and CDM groups. (C) Respiration Rates of ADNM and ADM groups. (D) Respiration Rates of CDNM and CDM groups. (E) Heart Rates of ADNM and ADM groups. (F) Heart Rates of CDNM and CDM groups. Data are presented as the mean \pm SEM. * $p<0.05$. 
A

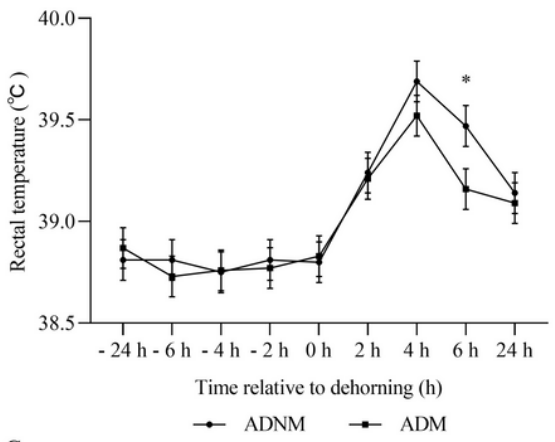

C

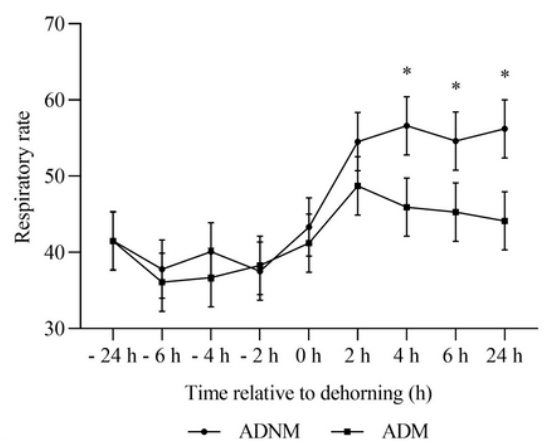

E

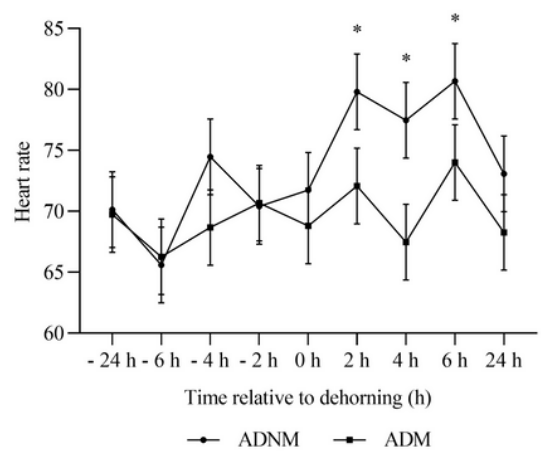

B
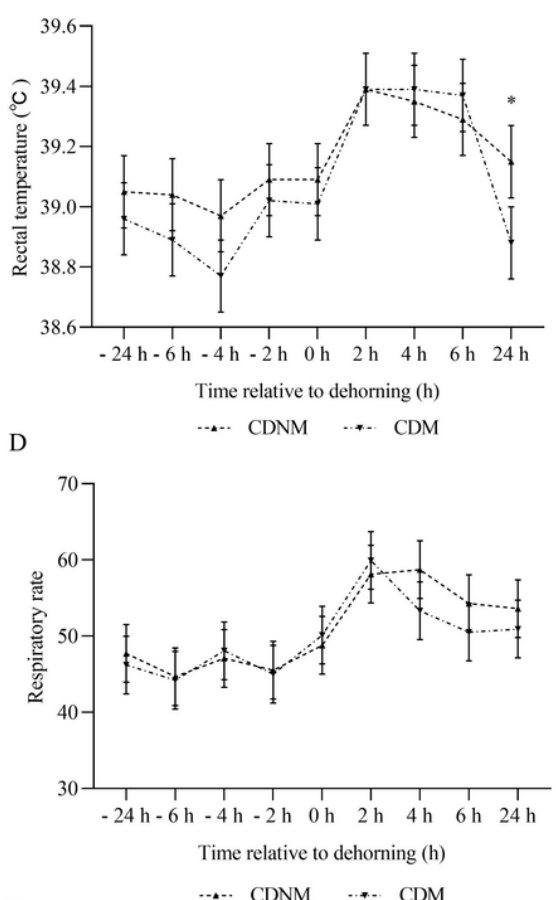

F

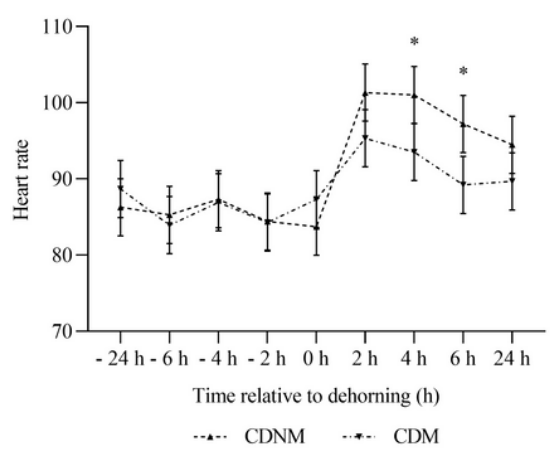

\section{Figure 1}

All data about Rectal Temperatures and Respiration and Heart Rates from -24 to $24 \mathrm{hr}$ of calves. (A) Rectal Temperatures of ADNM and ADM groups. (B) Rectal Temperatures of CDNM and CDM groups. (C) Respiration Rates of ADNM and ADM groups. (D) Respiration Rates of CDNM and CDM groups. (E) Heart Rates of ADNM and ADM groups. (F) Heart Rates of CDNM and CDM groups. Data are presented as the mean \pm SEM. * $p<0.05$. 
A

RH

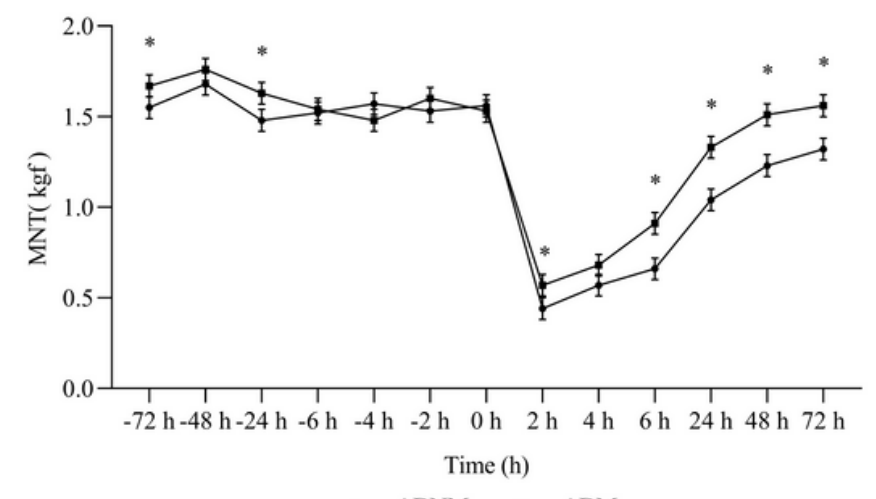

$\rightarrow \mathrm{ADNM} \rightarrow \mathrm{ADM}$

$\mathrm{C}$

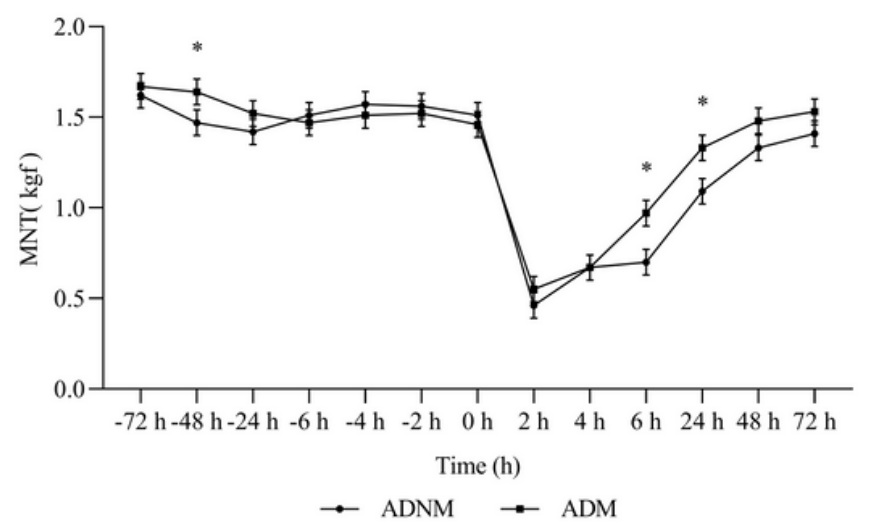

B

$\mathrm{RH}$

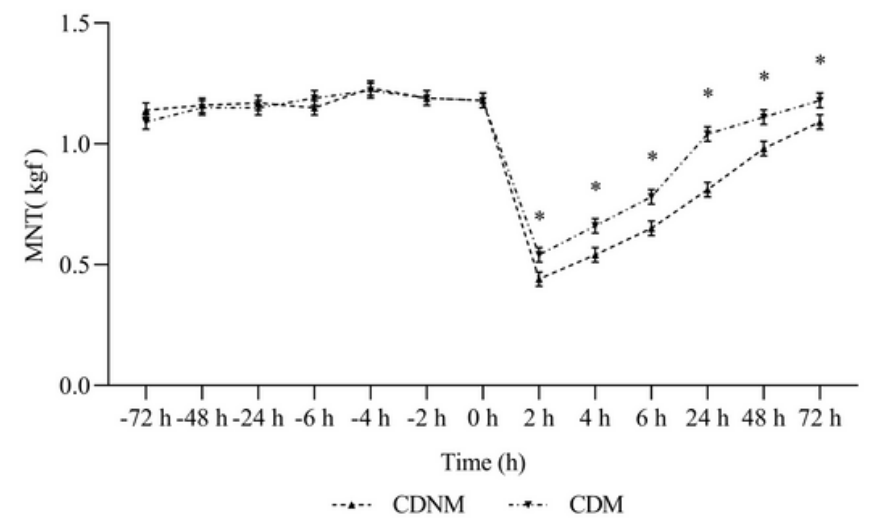

D

LH

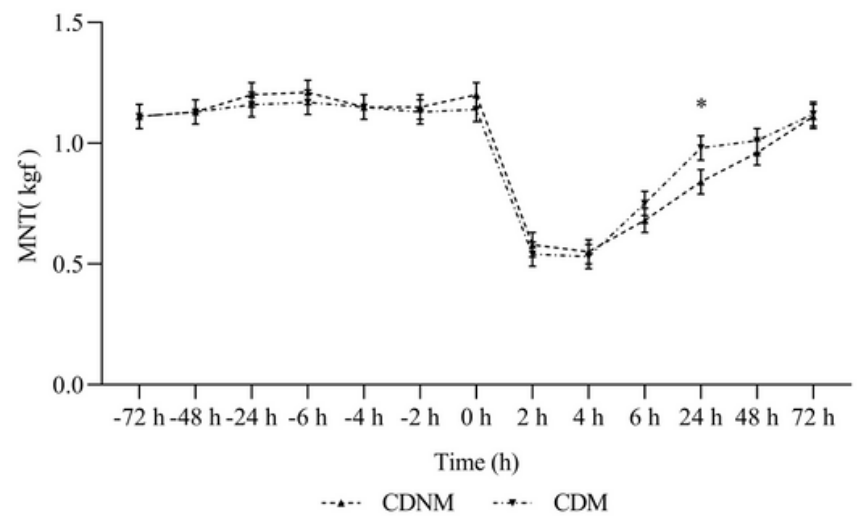

\section{Figure 2}

MNT values from -72 to $72 \mathrm{hr}$ Represented the average values of the four horn bud sites. (A) Mean \pm SEM MNTs from cattle's right horn (RH) of ADNM and ADM groups. (B) Mean \pm SEM MNTs from cattle's right horn (RH) of CDNM and CDM groups. (C) Mean \pm SEM MNTs from cattle's left horn (LH) of ADNM and ADM groups. (D) Mean \pm SEM MNTs from cattle's left horn (LH) of CDNM and CDM groups. ${ }^{*} p<0.05$. 
A

RH

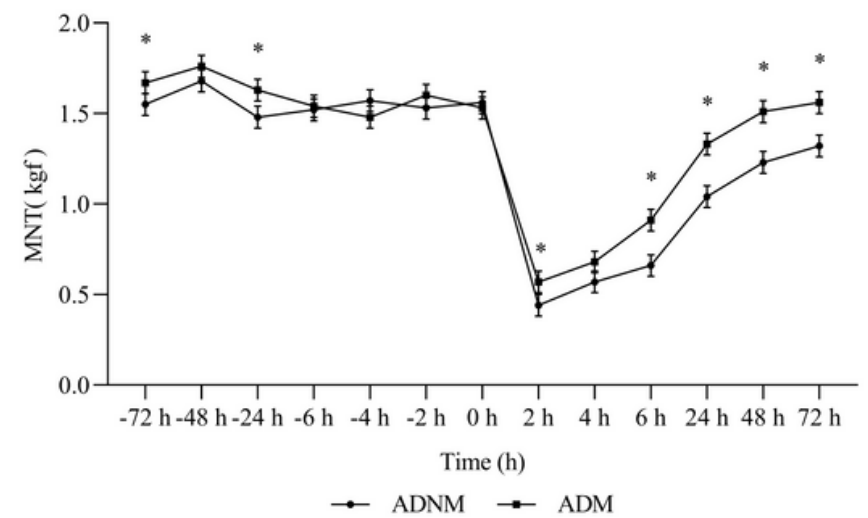

$\mathrm{C}$

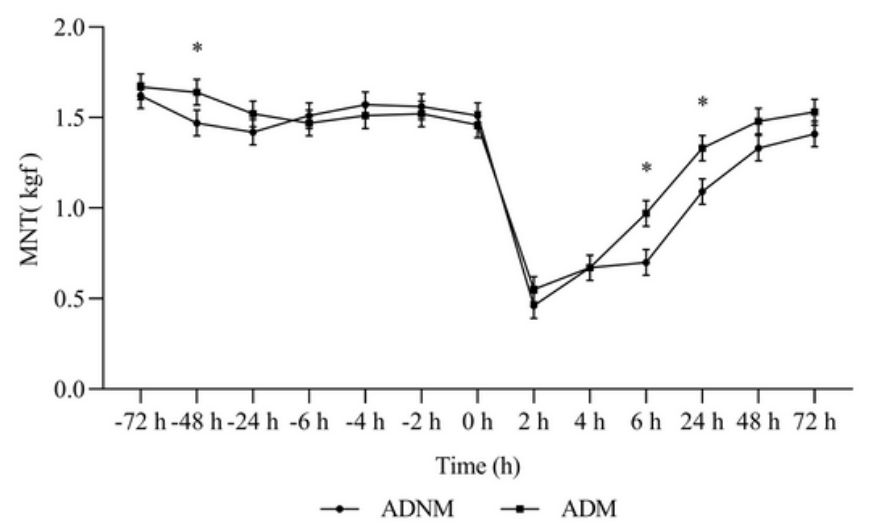

B

RH

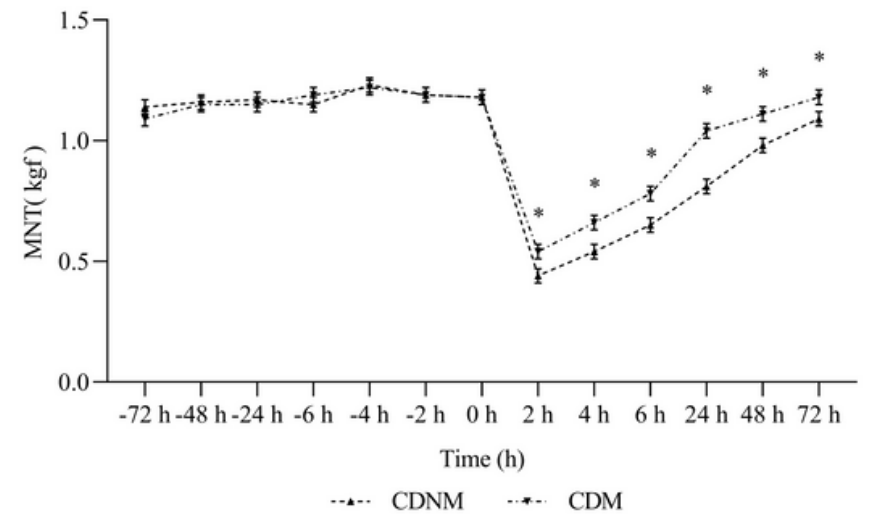

D

LH

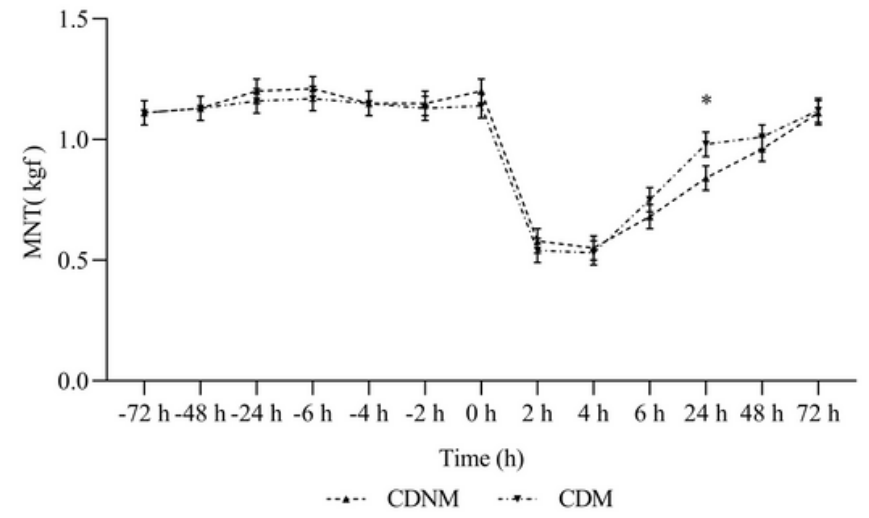

Figure 2

MNT values from -72 to $72 \mathrm{hr}$ Represented the average values of the four horn bud sites. (A) Mean \pm SEM MNTs from cattle's right horn (RH) of ADNM and ADM groups. (B) Mean \pm SEM MNTs from cattle's right horn (RH) of CDNM and CDM groups. (C) Mean \pm SEM MNTs from cattle's left horn (LH) of ADNM and ADM groups. (D) Mean \pm SEM MNTs from cattle's left horn (LH) of CDNM and CDM groups. ${ }^{*} p<0.05$. 

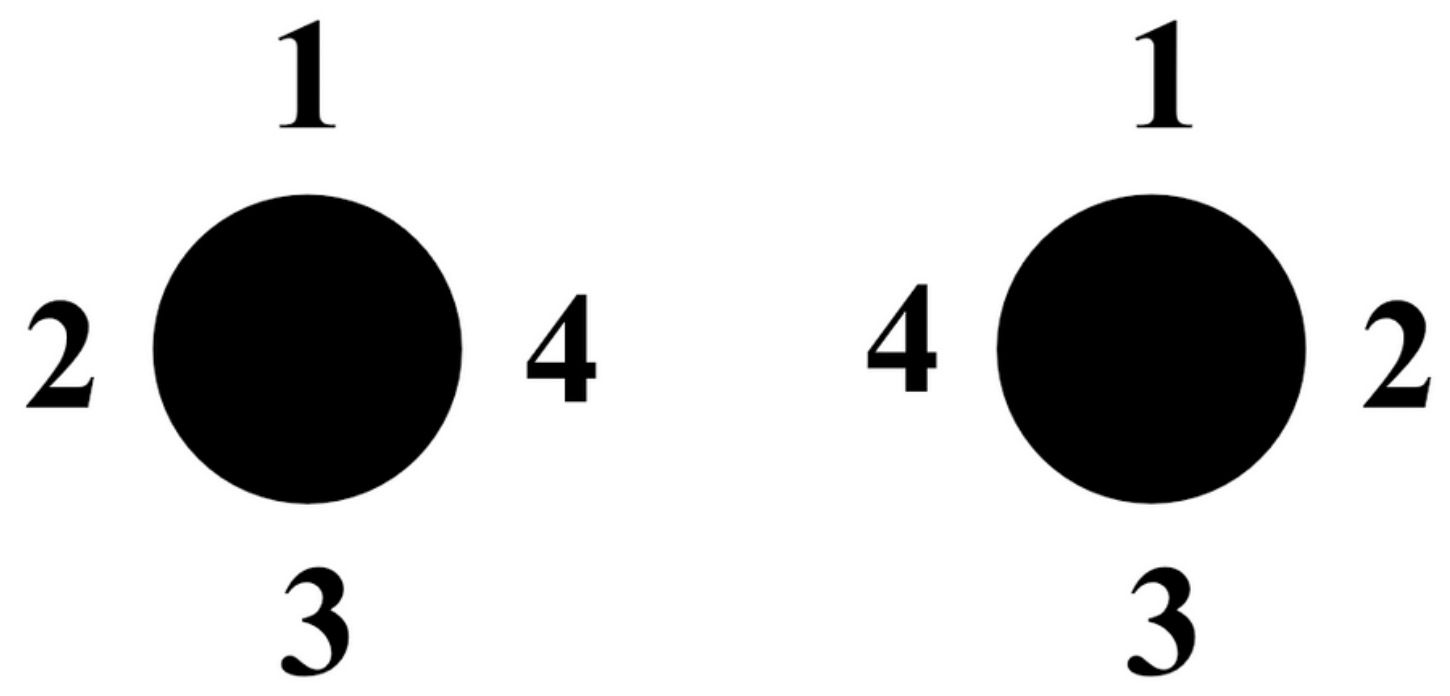

\section{Right horn Left horn}

Figure 3

Locations around the horn bud measured by pressure algometry. Sites are labelled to indicate the order in which they were measured.
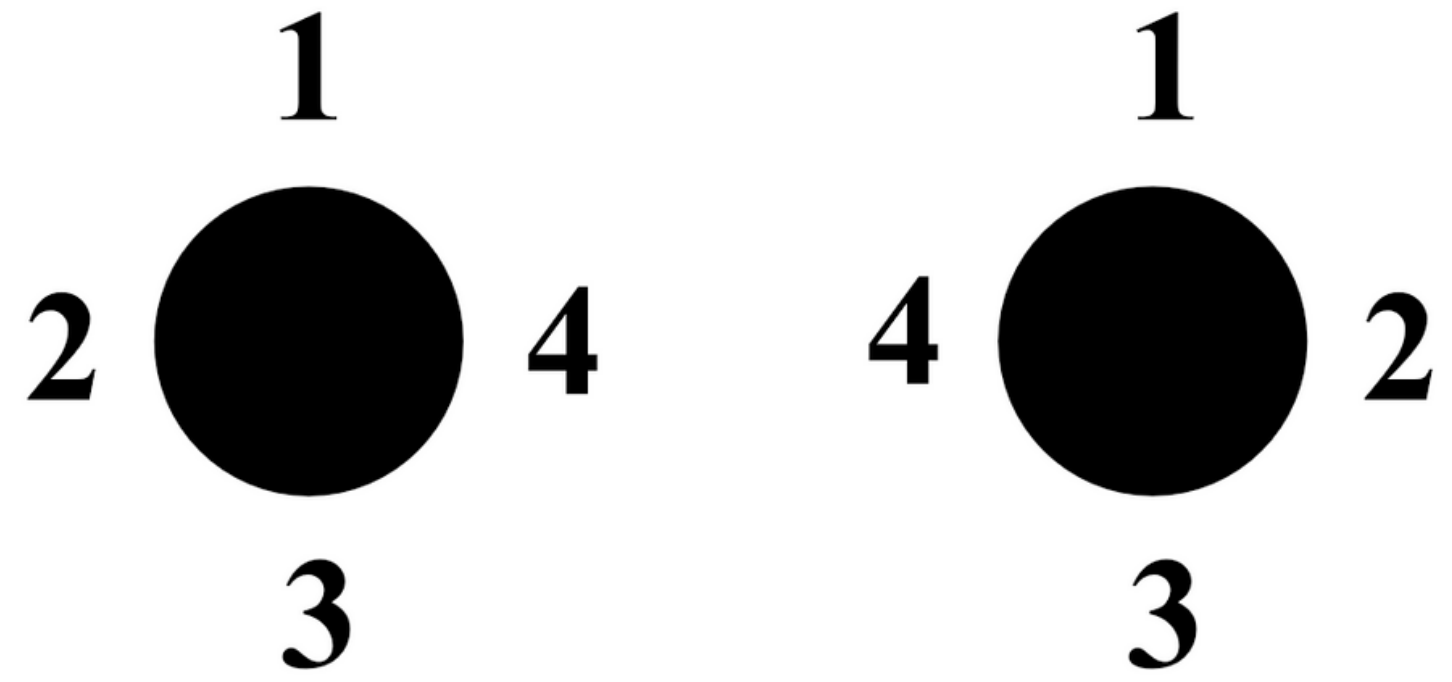


\section{Figure 3}

Locations around the horn bud measured by pressure algometry. Sites are labelled to indicate the order in which they were measured.

\section{Supplementary Files}

This is a list of supplementary files associated with this preprint. Click to download.

- Supplementarymaterial.docx

- Supplementarymaterial.docx 